\title{
ÍNDICES DE LOS VOLÚMENES I AL XXI
}

\section{Mario Portilla Chaves}

Con motivo del vigésimo aniversario de publicación de la Revista de Filología y Lingüística de la Universidad de Costa Rica, se han elaborado dos tipos de índices: uno de autores y otro temático. El índice de autores aparece ordenado alfabéticamente según el primer apellido del autor y el año de publicación del artículo. Además, cada entrada de este índice incluye una serie de descriptores temáticos, cuyo número promedio oscila entre tres y cuatro. El índice temático ha sido elaborado con base en los descriptores temáticos asignados a cada entrada del índice de autores. Por esta razón, los nombres propios de persona aparencen en este índice ordenados primero por el nombre seguido por el apellido. Por su parte, en el índice de autores, las referencias a los artículos aparecen ordenadas de la siguiente forma: primer apellido del autor, el año de publicación del volumen, título del artículo, volumen, número y páginas que comprende el artículo.

\section{ÍNDICE DE AUTORES}

Acuña, M. (1985). La primigenia cosmovisión poética de Mario Picado en Noche. 11(2): 53-7. Literatura costarricense, Mario Picado, Noche.

Acuña, M. (1986). Gagini: su producción poética. 12(2): 45-58. Literatura costarricense, Carlos Gagini.

Aguilar, J. (1986 (ANEJO)). A manera de introducción. Todo es ascenso. 12(1): 43. Literatura costarricense, creación, poesía.

Alvarado, M. (1989). Los actantes en la narración tradicional boruca. 15(2): 103-18. Lenguas indígenas de Costa Rica, boruca, narrativa oral.

Amoretti, M. (1976). Análisis del cuento "El caso del difunto Mr. Lewi Shame". Aplicación de la morfología del cuento de Vladimir Propp y otras aproximaciones. 2(2): 85-91. Morfología del cuento, Vladimir Propp. 
Amoretti, M. (1976). La cuentística de Fabián Dobles. 2(1): 39-47. Literatura costarricense, Fabián Dobles.

Amoretti, M. (1977). Dimensión profunda de Hombres de maíz. 3(1): 19-29. Literatura guatemalteca, Miguel Ángel Asturias, Hombres de maíz.

Amoretti, M. (1979). Camino a medio día. 5(1-2): 55-9. Literatura costarricense, Carmen Naranjo, Camino a medio día.

Amoretti, M. (1983). Comenzar por el comienzo o la teoría de los incipit. 9(1): 145-54. Teoría literaria, literatura costarricense, Virgilio Mora Rodríguez, Cachaza.

Amoretti, M. (1986). Dos preguntas en el aire. 12(2): 75-8. Literatura, sociedad, mesa redonda.

Amoretti, M. (1986). Goytisolo: objetividad y poesía. 12(1): 7-18. Literatura española, Juan Goytisolo, Juan de Manos.

Amoretti, M. (1988). La noción de efecto: un caso de pluriacentuación y transtextualidad en las teorías de Balibar y Macherey. 14(1): 7-10. Teoría literaria.

Amoretti, M. (1989). Rima de Vallbona: entre la permanencia y el exilio. 15(2): 23-7. Literatura costarricense, Rima de Vallbona.

Amoretti, M. (1989). Semiosis textual: simbiosis cultural. 15(1): 31-3. Teoría literaria, sociocrítica.

Amoretti, M. (1991). Reflexiones sobre la lectura. 17(1-2): 47-54. Teoría literaria, lectura.

Amoretti, M. (1992). Por una dialogística de la cultura. Aportes de Bajtín al pensamiento contemporáneo. 18(2): 7-8. Teoría literaria, Bajtin.

Amoretti, M. (1995). El odioso de Mora. 21(2): 7-16. Literatura costarricense, Virgilio Mora.

Araya, S. y. N. Molina. (1982). Exégesis de "Máscaras mexicanas" de Octavio Paz. 8(1-2): 815. Literatura mexicana, Octavio Paz, El laberinto de la soledad.

Araya, S., M. Bianchini y O. Durán. (1983). Pedro Arnáez: relato tradicional. 9(2): 15-34. Literatura costarricense, José Marín Cañas, Pedro Arnáez.

Arce, M. (1983). Algunas consideraciones sobre la innumerabilidad de los pronunciamientos lingüísticos. 9(2): 83-6. Pronunciamientos lingüísticos, niveles del lenguaje.

Arce, M. (1983). Pedro Páramo como imagen. 9(1): 167-74. Literatura mexicana, Juan Rulfo, Pedro Páramo. 
Arce, M. (1984). Estructura del cuento fantástico en Jorge Luis Borges. 10(2): 97-9. Literatura argentina, cuento fantástico, Jorge Luis Borges.

Arce, M. (1994). Un esquema formal para una interpretación funcionalista de las construcciones con SE en español. 20(2): 193-214. Español, morfosintaxis, construcciones con se.

Arce, M. et al. (1979). Materiales y pautas para la poética de Pablo Neruda. 5(1-2): 83-121. Literatura chilena, Pablo Neruda.

Arguedas, G. (1986). La colocación del sujeto y su relación con las categorías de primero y segundo plano en castellano. 12(1): 145-9. Español, morfosintaxis, análisis del discurso.

Arguedas, G. (1986). Morfología flexiva del misquito: el sustantivo. 12(2): 93-112. Lenguas índigenas de Nicaragua y Honduras, misquito, morfología.

Arguedas, G. (1987). La flexión verbal en misquito. 13(1): 115-27. Lenguas indígenas de Honduras y Nicaragua, misquito, morfosintáxis.

Arguedas, G. (1988). Los fonemas segmentales del protolenca: reconstrucción comparativa. 14(2): 89-109. Lenguas indígenas de El Salvador y Honduras, protolenca, fonología.

Arguedas, G. (1992). La tradición oral de los indígenas sumos: características y temática. 18(2): 53-8. Literatura indígena de Honduras, narrativa oral, sumo.

Arguedas, M. (1988). El realismo mágico en "Juan Girador". 14(2): 7-18. Literatura guatemalteca, leyenda, realismo mágico, Miguel Ángel Asturias, El espejo de Lida Sal.

Arguedas, M. (1993). El Quijote de la Mancha en El general en su laberinto. 19(1): 61-4. Literatura española, literatura latinoamericana, Miguel de Cervantes, Gabriel García Márquez, El Quijote de la Mancha, El general en su laberinto.

Arrieta, A. (1993). Tipología morfosintáctica del timote. 19(2): 99-110. Lenguas indígenas de Venezuela, timote, morfosintaxis, tipología.

Arrieta, G. (1986 (ANEJO). Poesía. 12(1): 44-5. Literatura costarricense, creación, poesía.

Arrieta, M. C. Jara y C. Pendones. (1986). Actitudes língüísticas hacia dos variedades de habla: Valle Central y Guanacaste. 12(2): 113-28. Español del Valle Central, español de Guanacaste, sociolíngüistica, actitudes lingüísticas.

Azofeifa, I. (1975). Mundo, vida y poesía o autolectura para explicarme. 1(2): 3-12. Literatura costarricense, Issac Felipe Azofeifa. 
Barboza, M. (1986 (ANEJO)). Tú y la Clepsidra. 12(1): 47. Literatura costarricense, creación, poesía.

Barnett, M. (1986 (ANEJO)). Soledad incontrolable. 12(1): 46. Literatura costarricense, creación, poesía.

Barzuna, G. (1978). Concepción del libertador americano en un poema de Pablo Neruda. 4(1): 7-12. Literatura chilena, Pablo Neruda.

Bertoglia, M. (1978). Gramática de casos y semántica generativa. 4(2): 31-8. Gramática de casos, semántica generativa.

Bertoglia, M. (1984). Young Goodman Brown de Nathaniel Hawthorne: una aproximación a sus claves. 10(2): 101-10. Literatura estadounidense, Nathaniel Hawthorne, Young Goodman Brown.

Bertoglia, M. (1989). La fonología de la lengua cacaopera. 15(1): 115-25. Lenguas indígenas de El Salvador, cacaopera, fonología.

Betancourt, H. y A. Constenla (1981). La expedición al territorio de los guatusos: una crónica colonial hispana y su contraparte en la tradición oral indígena. 7(1-2): 13-8. Literatura indígena de Costa Rica, guatuso, narraciones tradicionales, crónicas coloniales.

Bogarín, J. (1975). La oración como complemento de la frase nominal en inglés y español. 1(2): 29-48. Español, inglés, , morfosintaxis, gramática generativa transformacional.

Bolaños, L. (1987). Francisco Amighetti: poesía y artes plásticas. 13(2): 159-64. Literatura costarricense, Francisco Amiguetti.

Bolaños, L. (1987). Justo A. Facio: El primer poeta modernista de Costa Rica. 13(1): 89-96. Literatura costarricense, Justo A. Facio.

Bourland, D. (1975). Un análisis fonológico de cabécar. 1(2): 49-68. Lenguas indígenas de Costa Rica, cabécar, fonología.

Bourland, D. (1976). Una gramática generativa-transformacional del cabécar. 2(1): 49-112. Lenguas indígenas de Costa Rica, cabécar, morfosintaxis, gramática generativa transformacional.

Bourland, D. (1977). Hacia un paradigma no aristotélico para la lingüística. 3(1): 5-18. Teoría lingüística, Alfred Korzybski, paradigmas.

Brenes, A. (1987). Cocorí, de Joaquín Gutiérrez Mangel: otro punto de vista. 13(2): 165-8. Literatura costarricense, Joaquín Gutiérrez Mangel, Cocorí. 
Burdiel, M. (1978). Una introducción al simbolismo fonético. 4(1): 1-6. Estilística.

Burdiel, M. (1986). El libro de Tobit y el cuento maravilloso. 12(1): 69-76. Literatura bíblica, Tobit, cuento maravilloso.

Calvo, A. (1990). El plural en los sustantivos terminados en vocal en el cantón de Curridabat: Estudio cuantitativo. 16(2): 75- 83. Español de Costa Rica, sociolingüística, morfología, formación del plural nominal en español.

Calvo, A. (1995). Variación fonética de / f / y / r / en el habla culta de San José. 21(1): 115-34. Español de Costa Rica, habla culta, fonología, fonema / $\mathrm{f} /$, fonema / $\mathrm{r}$ /.

Camacho, J. (1975). Apuntes críticos sobre la poesía de Roberto Brenes en busca de un esquema poético. 1(1): 33-43. Literatura costarricense, Roberto Brenes Mesén.

Camacho, J. (1977). Análisis de un poema de Antonio Machado: "El limonero lánguido suspende". 3(1): 73-95. Literatura española, Antonio Machado.

Camacho, J. (1979). Algo más sobre el poema XXXII de Antonio Machado. 5(1-2): 5-21. Literatura española, Antonio Machado.

Camacho, J. (1984). El sentido profundo de la poesía en un texto de Vicente Aleixandre. 10(2): 89-95. Literatura española, Vicente Aleixandre, Espadas como labios.

Camacho, J. (1988). "Débil del alba", entre la interpretación y la lectura. 14(1): 31-44. Literatura chilena, Pablo Neruda, Residencia en la tierra.

Camacho, J. (1990). Deconstruccionismo norteamericano: revolución y tradición. 16(1): 7-13. Teoría literaria, crítica literaria, deconstruccionismo.

Campos, G. (1986 (ANEJO)). La pareja diez. 12(1): 15-6. Literatura costarricense, creación, cuento.

Carmona, R. (1986 (ANEJO)). Poesía. 12(1): 48. Literatura costarricense, creación, poesía.

Castanedo, C. y. B. Lininger (1985). Estudio exploratorio psicolingüístico del comportamiento sintáctico en el deficiente mental. 11(1): 105-17. Psicolingüítica, morfosintaxis, síndrome de Down.

Cervantes, L. (1991). La temática de los cantos fúnebres bribris. 17(1-2): 81-104. Lenguas indígenas de Costa Rica, bribri, cantos fúnebres.

Chavarría, G. (1986 (ANEJO)). Lluvia; Verano. 12(1): 49. Literatura costarricense, creación, poesía. 
Chavarría, G. (1995). La voz lírica en el poema "Canto fúnebre a la muerte de Joaquín Pasos" de Carlos Martínez Rivas. 21(1): 35-46. Literatura nicaragüense, Carlos Martínez Rivas, La insurrección solitaria.

Chavarría, O. (1976). Aspectos del método de Panini. 2(2): 65-72. Sánscrito, Panini.

Chavarría, O. (1976). El metalenguaje de Panini. 2(1): 3-9. Sánscrito, Panini.

Chavarría, O. (1977). La ortografía de las Concherías. 3(1): 45-53. Literatura costarricense, Aquileo Echeverría, Concherías.

Chaverri, A. (1987). La marque du titre. 13(1): 7-30. Teoría literaria, Leo Hoek, La marque du titre.

Chaverri, A. (1991). Relaciones intertitulares a partir de Retorno al Kilimanjaro. 17(1-2): 21-7. Literatura costarricense, Fernado Durán Ayanegui, Retorno al Kilimanjaro.

Chaverri, A. (1993). Viaje al reino de los deseos: aventuras/busquedas/géneros. 19(1): 65-73. Literatura costarricense, Rafael Angel Herra,Viaje al reino de los deseos.

Chaves, I. (1986 (ANEJO)). A Pablo Neruda. 12(1): 50. Literatura costarricense, creación, poesía.

Chaves, I. (1993). El código de veredicción mítico en el poema “Amor América (1400)", primer poema del Canto general de Pablo Neruda. 19(1): 19-60. Literatura chilena, Pablo Neruda, Canto general.

Chen, J. (1986 (ANEJO)). Hamlet: viaje trágico y proceso de identidad. 12(1): 35-9. Literatura costarricense, creación, ensayo.

Chen, J. (1990). Hacia una lectura de la estrategia paratextual del Fray Gerundio de Campazas: la fuerza centrípeta del prólogo autorial. 16(2): 7-24. Literatura española, José Francisco de Isla, Fray Gerundio de Campazas.

Chen, J. (1991). La teoría del paratexto y el Fray Gerundio de Campazas: la puesta en escena de una retórica de lo liminar. 17(1-2): 7-19. Literatura española, José Francisco de Isla, Fray Gerundio de Campazas.

Chen, J. (1992). La sociocrítica y su inscripción en el campo de la teoría literaria. 18(2): 9-15. Teoría literaria, sociocrítica.

Chen, J. (1992). Profundidad y dualismo: el doble protocolo de lectura en Meditaciones del Quijote. 18(1): 7-18. Literatura española, José Ortega y Gasset, Meditaciones del Quijote. 
Chen, J. (1993). Discurso autobiográfico y proceso de autentificación en Cárcel de Amor de Diego de San Pedro. 19(2): 7-15. Literatura española, novela sentimental, Diego de San Pedro, Cárcel de Amor.

Chen, J. (1993). La escatología al servicio de la efectividad política en Crónicas romanas de Alfonso Sastre. 19(1): 25-34. Literatura española, Alfonso Sastre, Crónicas romanas.

Chen, J. (1994). El criticismo de los novatores: motor de la primera biografía cervantina, escrita por Gregorio de Mayáns. 20(2): 7-17. Miguel de Cervantes, biografía, Gregorio de Mayáns.

Chen, J. (1994). La súplica colectiva y la palabra redentora en "Oración por Marilyn Monroe": un acercamiento pragmático. 20(1): 25-34. Literatura nicaragüense, Ernesto Cardenal.

Chen, J. (1995). Autobiografía y relato de formación en La lámpara maravillosa. 21(1): 7-15. Literatura española, Ramón del Valle-Inclán, La lámpara maravillosa.

Chen, J. (1995). Perfecit de denegación final del contrato historiográfico en el Fray Gerundio de Campazas. 21(2): 83-90. Literatura española, José Francisco de Isla, Fray Gerundio de Campazas.

Chinchilla, K. (1991). Entre el Adán y el Golem, a propósito de un poema de Jorge Luis Borges. 17(1-2): 63-71. Literatura argentina, Jorge Luis Borges.

Chinchilla, K. (1992). Categorías universales del pensamiento mítico en la tradición cosmogónica y escatológica. 18(1): 47-53. Mitología, griegos y aztecas.

Chinchilla, K. (1993). La leyenda de la laguna del Volcán Barva. 19(2): 83-6. Folclor, narrrativa oral, leyenda.

Chinchilla, K. (1994). José Arcadio Buendía y la lucha demoníaca hacia la valoración mística de la alquimia en el Rosarium philosophorum de 1550. 20(2): 121-44. Literatura comparada, literatura colombiana, Gabriel García Márquez, Cien años de soledad.

Chinchilla, K. (1995). El incesto en Cien años de soledad: ¿un camino liberador hacia la integración de la estirpe? 21(2): 17-40. Literatura colombiana, Gabriel García Márquez, Cien años de soledad.

Chinchilla, K. (1995). La tradición del hermafrodito o andrógino en la Antigüedad y la Edad Media. 21(1): 17-33. Mitología.

Conejo, M. (1982). La imagen del agua en Dafnis y Cloe. 8(1-2): 87-90. Literatura griega, novela pastoril. 
Conejo, M. (1985). Actualidad de la crítica política en Los caballeros de Aristófanes. 11(2): 619. Literatura griega, Aristófanes, Los caballeros.

Conejo, M. (1985). La persuasión homérica precursora de la retórica. 11(1): 31-8. Literatura griega, Homero, retórica

Conejo, M. (1987). Los siete sabios de Grecia. Enfoque crítico. 13(2): 95-101. Los siete sabios de Grecia.

Conejo, M. (1988). El sabio confidente en la prosa de Herodoto. 14(2): 65-9. Literatura griega, historiografía, Herodoto.

Constenla, A. (1977). La terminología del parentesco de los indios borucas. 3(1): 30-8. Lenguas indígenas de Costa Rica, boruca, lexicología.

Constenla, A. (1982a). La nasalización en relación con el tono y la intensidad en bribri. 8(1-2): 109-12. Lenguas indígenas de Costa Rica, bribri, fonología, nasalización.

Constenla, A. (1982b). Seis narraciones tradicionales guaymíes (moves). 8(1-2): 103-7. Literatura indígena de Costa Rica, guaymí.

Constenla, A. (1982c). Sobre la construcción ergativa en la lengua guatusa. 8(1-2): 97-101. Lenguas indígenas de Costa Rica, guatuso, morfosintaxis, ergativo.

Constenla, A. (1983). Descripción del sistema fonemático del guatuso. 9(1): 3-20. Lenguas indígenas de Costa Rica, guatuso, fonología.

Constenla, A. (1984). El huetar: observaciones sobre los materiales disponibles para su estudio y sobre las hipótesis en torno a sus afinidades lingüísticas. 10(2): 3-18. Lenguas indígenas de Costa Rica, huetar.

Constenla, A. (1985). Funciones del presente histórico en dos textos narrativos tradicionales costarricenses. 11(1): 41-61. Narración tradicional hispana costarricense, análisis del discurso, presente histórico.

Constenla, A. (1985). Las lenguas dorasque y chánguena y sus relaciones genealógicas. 11(2): 81-91. Lenguas indígenas de Panamá, dorasque, chánguena, relaciones genealógicas.

Constenla, A. (1986). Textos bilingües de cuatro narraciones tradicionales borucas. 12(1): 79101. Litertura índigena de Costa Rica, boruca.

Constenla, A. (1987). Elementos de fonología comparada de las lenguas misumalpas. 13(1): 129-61. Lenguas indígenas de Honduras y Nicaragua, familia misumalpa, misquito, sumo y matagalpa, fonología comparada. 
Constenla, A. (1988). Indicios para la reconstrucción de clasificadores en el sintagma nominal protochibcha. 14(2): 111-8. Lenguas indígenas de Costa Rica, protochibcha, reconstrucción morfosintáctica, clasificadores.

Constenla, A. (1990). Introducción al estudio de las literaturas tradicionales chibchas. 16(1): 55-96. Literatura indígena, lenguas chibchas.

Constenla, A. (1990). Una hipótesis sobre la localización del protochibcha y la dispersión de sus descendientes. 16(2): 110-26. Lenguas indígenas de Costa Rica, protochibcha.

Constenla, A. (1992). Hagiografía y antihagiografía en la tradición oral guatusa. 18(1): 83-124. Literatura indígena de Costa Rica, guatuso, hagiografía, antihagiografía.

Constenla, A. (1995). Sisimique: orígenes indígenas de un personaje del cuento popular costarricense. 21(2): 159-66. Víctor Manuel Arroyo, narrativa oral, Sisimique.

Constenla, A. y E. Margery (1991). Elementos de fonología comparada chocó. 17(1-2): 137-91. Lenguas indígenas de Panamá y Colombia, chocó, fonología comparada.

Constenla, A. y F. Pereira. (1989). Afinidades mesoamericanas del mito talamanqueño de los dioses de las tormentas. 15(2): 75-102. Literatura indígena de Costa Rica, bribri, mitología.

Contreras, F. (1986 (ANEJO)). Su oficio de escritor. 12(1): 11-2. Literatura costarricense, creación, cuento.

Corneli, C. (1977). En torno al análisis formal de la lírica griega. 3(1): 39-42. Literatura griega, métrica.

Coronas, G. (1994). Análisis fonológico de la lengua andaquí. 20(1): 69-98. Lenguas indígenas de colombia, fonología.

Coronas, G. (1995). El léxico andaquí. 21(1): 79-113. Léxico, andaquí.

Cortés, M. (1989). Hacia una problematización del discurso dramático: Cañas, Gallegos y Rovinski. 15(1): 41-54. Literatura costarricense, Alberto Cañas, Daniel Gallegos, Samuel Rovinski.

Cosmas, N. (1992). El modelo lingüístico matemático del género gramatical y su aplicación en la lengua española. 18(2): 61-9. Lingüística matemática, Salomón Marcus.

Dalton, C. (1978). El llano en llamas: un estudio de la negatividad. 4(2): 47-58. Literatura mexicana, Juan Rulfo, El llano en llamas. 
Dalton, C. (1980). Pedro Páramo: un análisis de la negatividad. 6(1-2): 69-80. Literatura latinoamericana, Juan Rulfo, Pedro Páramo.

Dalton, C. (1981). Psicoanálisis de don Torcuato y doña Talamanca, dos personajes de Cocorí. 7(1-2): 79-82. Literatura costarricense, Joaquín Gutiérrez, Cocorí, psicoanálisis.

Delgado, C. (1991). Actitudes y motivación en el aprendizaje de una lengua extranjera. 17(1-2): 203-17. Lingüística aplicada, enseñanza y aprendizaje de lenguas extranjeras.

Delgado, M. (1990). El uso de captadores de atención por niños en ambientes formales e informales. 16(2): 85-92. Sociolingüística, captadores de atención.

Díaz, A. (1992). Tentatives d' evasión. 18(2): 43-9. Literatura francesa, Julien Green, Epaves.

Díaz, L. (1976). Procesos de similitud y continuidad semántica en "Sola la voz" de Hugo Lindo. 2(1): 35-7. Literatura salvadoreña, Hugo Lindo.

Dickeman, M. (1982). Hacia la búsqueda de una relación entre lenguaje y cultura: reflexiones de una lingüísta. 8(1-2): 113-20. Lengua y cultura.

Dickeman, M. (1985). Eliminación de la ambigüedad pronominal en el discurso del criollo limonense. 11(1): 119-30. Criollo inglés de Limón, análisis del discurso, referencia pronominal.

Durán, J. (1982). Un caso de relación literaria: Emile Zolá y Joaquín García Monge. 8(1-2): 37-43. Literatura costarricense, Joaquín García Monge, Emile Zolá.

Escoto, J. (1982). La lógica de la degradación en La propia de Magón. 8(1-2): 31-6. Literatura costarricense, Manuel González Zeledón, La propia.

Fallas, L. (1991). Docimologie: critères de correction. 17(1-2): 237-45. Traductología.

Fáuaz, L. (1987). Don Quijote de la Mancha. Cristianización de un Fata. 13(2): 7-23. Literatura española, Miguel de Cervantes, Don Quijote de la Mancha.

Fáuaz, L. (1988). Tres relatos moriscos en Don Quijote. 14(1): 19-30. Literatura española, Miguel de Cervantes, Don Quijote.

Fernández, A. (1982). Costarriqueñismo universal en Leyendas y escenas campesinas de Joaquín García Monge. 8(1-2): 74-80. Literatura costarricense, Joaquín García Monge, Leyendas y escenas campesinas, costumbrismo.

Flores, B. y X. Rodríguez (1994). The influence of language transfer on consonant cluster production. 20(1): 99-112. Lingüística aplicada, fonología, inglés, español. 
Fonseca, V. (1975). No quiero ser segua o afán de perennidad de belleza. 1(2): 69-74. Literatura costarricense, Alberto Cañas, La segua.

Friedemann, N. (1990). Lumbalú: Ritos de la muerte en Palenque de San Basilio, Colombia. 16(2): 51-63. Folclorística.

Gaínza, G. (1975). La mostración lingüística y la autonomía sintáctica. 1(1): 45-53. Teoría lingüística.

Gaínza, G. (1975). Lo consabido: mostración de la experiencia. 1(2): 74-80. Teoría lingüística.

Gaínza, G. (1976). El español de Costa Rica: breve consideración acerca de su estudio. 2(2): 79-84. Español de Costa Rica, historia de la lingüística.

Gaínza, G. (1982a). Condiciones ecónomico-políticas de los procesos diglósicos. 8(1-2): 125-8. Diglosia.

Gaínza, G. (1982b). Notas sobre el valor semiótico de los gestos. 8(1-2): 121-4. Semiótica, gestos.

Garita, F. y M. Quesada. (1988). La mujer, "sujeto hablado" en la novela Murámonos Federico. 14(1): 61-6. Literatura costarricense, Joaquín Gutiérrez, Murámonos Federico.

Gei, O. (1986 (ANEJO)). Poesía. 12(1): 51. Literatura costarricense, creación, poesía.

Giglioni, G. (1985). La formación intelectual y política del joven Luckács. 11(2): 125-34. George Luckács.

Giralt, M. (1985). La dimensión semántica de Xavier Zubiri. 11(1): 138-45. Xavier Zubiri.

Goño, L. (1986 (ANEJO)). (Poesía sin título.) 12(1): 52. Literatura costarricense, creación, poesía.

González, J. (1975). Pedro Páramo: Sus contenidos y formas en relación con la novela hispanoamericana en general y con la mejicana en particular. 1(1): 21-32. Literatura mexicana, Juan Rulfo, Pedro Páramo.

González, J. (1985). Teoría y práctica del cuento en Hispanoamérica: el caso de Horacio Quiroga. 11(1): 5-14. Literatura uruguaya, Horacio Quiroga.

González, J. (1990). Discurso de incorporación a la Academia Costarricense de la Lengua correspondiente a la Real Academia Española. 16(2): 127-33. Carlos Luis Sáenz.

Haba, E. (1983). Algunos aspectos de la letra del tango. 9(1): 175-86. Tango. 
Hernández, F. (1986). Dubliners or the feeling of frustration. 12(2): 137-52. Literatura irlandesa, James Joyce, Dublineses.

Hernández, F. (1986). Dublineses: mecanismos de evasión de algunos personajes. 12(1): 53-64. Literatura irlandesa, James Joyce, Dublineses.

Herra, M. (1976). Un viejo tema, un nuevo enfoque: formalización isotópica de "Cima del gozo" de Isaac Felipe Azofeifa. 2(1): 17-34. Literatura costarricense, Isaac Felipe Azofeifa.

Herrera, B. (1978). La soledad y el tiempo en Gabriel García Márquez. 4(2): 1-15. Literatura colombiana, Gabriel García Márquez.

Herrera, B. (1981). Mundo y conciencia en un novela de Roberto Arlt. 7(1-2): 35-42. Literatura argentina, Roberto Arlt, El juguete rabioso.

Herrera, B. (1984). De La hojarasca a El otoño del patriarca: tras la esencia del poder. 10(1): 15-30. Literatura colombiana, Gabriel García Márquez.

Herrera, B. (1986). Borges y el lenguaje. 12(2): 7-23. Literatura argentina, Jorge Luis Borges.

Herrera, B. (1987). Borges y el conocimiento. 13(1): 71-87. Literatura argentina, Jorge Luis Borges.

Herrera, B. (1987). Borges y la literatura. 13(2): 35-50. Literatura argentina, Jorge Luis Borges.

Herzfeld, A. (1978). Vida o muerte del criollo limonense. 4(2): 17-24. Criollo inglés de Limón, sustitución lingüística.

Herzfeld, A. (1994). Language and identity: the black minority of Costa Rica. 20(1): 113-42. Criollo inglés de Limón, actitudes linguísticas.

Hidalgo, D. (1977). Aspectos de la comunicación no verbal. 3(1): 69-72. Comunicación no verbal, influencia de la cultura.

Hidalgo, D. (1978). La ambigüedad lingüística, 4(2): 39-45. Ambigüedad lingüística, español, inglés.

Hidalgo, D. (1979). Manifestaciones semámticas. 5(1-2): 23-9. Ambigüedad lingüística, gramática generativa.

Him, R. (1992). Los complementos predicativos y la distribución del PRO. 18(1): 139-61. Complementos Predicativos, verbos ser y estar. 
Idoyaga, A. (1989). Tiempo, espacio y existencia. Análisis de los seres míticos pilagá. 15(2): 39-50. Literatura indígena de Argentina, pilagá, mitología.

Idoyaga, A. (1990). Iniciación femenina, proceso de gestación, alumbramiento, aborto e infanticidio entre los mataco, toba y pilagá. 16(2): 65-71. Folclorística, mataco, toba, pilagá.

Idoyaga, A. (1992). Taxonomía y cosmovisión en la etnozoología pilagá. 18(1): 57-72. Lenguas indígenas de Argentina, pilagá, etnozoología.

Jara, C. (1986 (ANEJO)). Marina; Eunice; Novena; En algún sonido; La araucaria. 12(1): 53-4. Literatura costarricense, creación, poesía.

Jara, C. (1986). Recopilación y análisis de "Juegos de palmadas". 12(1): 103-21. Producción verbal, juegos infantiles tradicionales, juegos de palmadas.

Jara, C. (1987). "Elegía de un madrigal" o la muerte de la poesía. 13(1): 63-9. Literatura española, Antonio Machado.

Jara, C. (1988). El léxico de origen indígena en la norma culta de San José. 14(1): 109-24. Español de Costa Rica, léxico de origen indígena, habla culta de San José.

Jara, C. (1989). Análisis componencial del parentesco bocotá de Chiriquí. 15(2): 131-41. Lenguas indígenas de Panamá, bocotá, lexicología, análisis componencial.

Jara, C. (1995). Transitividad en el discurso bribri. 21(2): 91-103. Lenguas indígenas de Costa Rica, bribri, morfosintaxis, análisis del discurso.

Jiménez, J. (1977). Temporalidad del gerundio. 3(2): 43-50. Gerundio, temporalidad, español.

Jiménez, J. (1981). Estudio diacrónico del gerundio español. 7(1-2): 13-8. Gerundio, cambio lingüístico, español.

Jiménez, J. (1988). Caracterización de la prosa de Tucídides. 14(2): 71-6. Literatutra griega, historiografía, Tucídides.

Jiménez, J. (1989). La cantidad en latín. 15(1): 57-65. Latín, fonología, cantidad vocálica.

Kuramochi, Y. (1993). Interacción de personas con seres del volcán en: "Degünche”, un relato mapuche. 19(1): 113-26. Literatura indígena de Chile, mapuche.

Láscaris, C. (1977). Las canciones de los peces de Federico García Lorca, hijo de agua. 3(2): 67-84. Literatura española, Federico García Lorca. 
Lininger, B. (1977). La frase nominal del dialecto brorán del térraba. 3(2): 85-92. Lenguas indígenas de Costa Rica, térraba, morfosintaxis.

Lininger, B. (1978). Chomsky y algunas facetas de la teoría lingüística. 4(1): 47-53. Teoría lingüística, gramática generativa transformacional.

Lininger, B. (1981). Estudios sobre el guaymí ngäbere: fonología, alfabeto y diccionario provisional. 7(1-2): 101-15. Lenguas indígenas de Costa Rica, guaymí, fonología, alfabeto práctico.

Lininger, B. (1982). Alfabeto práctico ngäbere y las listas ilustrativas. 8(1-2): 137-54. Lenguas indígenas de Costa Rica, guaymí, alfabeto práctico.

Lininger, B. (1984). Influencia del Síndrome de Down en la adquisición de la sintaxis. 10(2): 19-61. Psicolingüística, morfosintaxis.

Lininger, B. et al. (1978). Un análisis fonológico de un idiolecto del brorán (térraba). 4(1): 5574. Lenguas indígenas de Costa Rica, térraba, fonología.

López, A. (1983). La teoría gramatical de Andrés Bello. 9(1): 75-102. Historia de la linguística, Andrés Bello.

López, A. (1985). Teoría de las partes de la oración en la gramática de Andrés Bello. 11(1): 91103. Andrés Bello, partes de la oración.

López, M. (1988). Directrices temáticas en tres cuentos de Rima de Vallbona. 14(1): 67-72. Literatura costarricense, Rima de Vallbona, Mujeres y agonías.

Macaya, E. (1976). Una visión estructural del Hipólito de Eurípides. 2(2): 5-64. Literatura griega, Eurípides, Hipólito.

Macaya, E. (1981). Paradoja, metáfora y símbolo en "Débil del alba" de Pablo Neruda. 7(2): 117-20. Literatura chilena, Pablo Neruda.

Macaya, E. (1983). El lazarillo de Tormes: la evolución picaresca y la comicidad. 9(1-2): 12334. Literatura española, El lazarillo de Tormes.

Margery, E. (1975). Alcances en torno a la problemática del narrador. 1(1): 55-82. Teoría literaria, narrador.

Margery, E. (1977). Los criterios binaristas en la teoría literaria. Notas en torno a sus posiciones y fundamentos. 3(2): 23-41. Teoría literaria, criterios binaristas. 
Margery, E. (1982). Sobre el motivo literario. 8(1-2): 3-26. Teoría literaria, motivo literario.

Margery, E. (1985). Alfabeto práctico pandialectal de la lengua cabécar. 11(1): 131-7. Lenguas indígenas de Costa Rica, cabécar, alfabeto práctico.

Margery, E. (1985). Morfemas derivativos en la cualificación nominal de cabécar. 11(2): 98110. Lenguas indígenas de Costa Rica, cabécar, morfología.

Margery, E. (1986). Etnoespantología cabécar. 12(1): 153-88. Lenguas indígenas de Costa Rica, cabécar, lexicología, análisis componencial.

Margery, E. (1987). Seis problemas para don Isidro Parodi. Notas para su interpretación con alcances sobre el género policial. 13(2): 61-91. Literatura argentina, Jorge Luis Borges, Seis problemas para don Isidro Parodi.

Margery, E. (1989). Cuatro relatos mitológicos bocotás de los ye nansere (seres malos). 15(2): 51-74. Literatura indígena de Panamá, bocotá, mitología.

Margery, E. (1990). La leyenda del origen de Jirondái en una versión bocotá de Chiriquí: texto y comentarios. 16(1): 97-110. Literatura indígena de Panamá, bocotá.

Margery, E. (1991). En torno a las actancias del mito de "La obtención del fuego" en la narrativa oral indoamericana . 17(1-2): 105-22. Literatura indígena americana, narrativa oral, mitología.

Margery, E. (1992). Apuntes sobre tres versiones bocotás de la leyenda de "La madre del maíz". 18(1): 75-81. Literatura indígena de Panamá, bocotá.

Margery, E. (1993). Dos textos y algunos comentarios en relación con el rol de trickster de la guatusa (Dasyprocta Punctata) en la narrativa oral de los bocotás de Chiriquí. 19(2): 71 9. Literatura indígena de Panamá, bocotá.

Margery, E. (1993). Textos y comentarios de cuatro relatos bocotás referentes a cataclismos. 19(1): 89-111. Literarura indígena de Panamá, bocotá, cataclismología.

Margery, E. (1994). Notas y comentarios sobre motivos concurrentes en algunas versiones indoamericanas del mito de "la larga noche". 20(2): 147-90. Mitología indígena americana.

Margery, E. Sobre el desarrollo y la distribución geográfica del motivo de la misteriosa ama de casa (N831.1) en la tradición oral indoamericana. 21(2): 105-29. Literatura indígena, mitología.

Marín, M. (1986 (ANEJO)). Guernica. 12(1): 55. Literatura costarricense, creación, poesía. 
Masís, O. y. E. Mora (1985). Las oraciones completivas en el criollo de Limón: análisis sintáctico de un ideolecto. 11(2): 111-21. Criollo de Limón, morfosintáxis.

Mayer, P. von (1991). Problema genérico en torno a El general en su laberinto. 17(1-2): 73-7. Literatura colombiana, Gabriel García Márquez, El general en su laberinto.

Medina, D. (1991). Recurrencia del tema del Don Juan: Hipótesis en torno a la teoría literaria o (Don Juan: Pre-textos para una teoría de la escritura). 17(1-2): 39-46. Teoría literaria, Don Juan.

Mejía, J. (1976). Verbos transitivos e intransitivos de dos palabras en inglés. 2(2): 73-7. Gramática generativa transformacional, morfosintaxis, inglés.

Meyer, K. (1991). The Kilimanjaro kaleidoscope: a sociocritical apprach to Retorno al Kilimanjaro. 17(1-2): 29-38. Literatura costarricense, Fernado Durán Ayanegui, Retorno al Kilimanjaro, sociocrítica.

Meyers, K. (1990). Billy as lily: a feminist reading of Billy Budd. 16(2): 35-40. Literatura estadounidense, Herman Melville, Billy Budd.

Meyers, K. (1990). Great Expectations: Creative mythology in Dickens. 16(1): 47-52. Literatura inglesa, Charles Dickens, Great Expectations.

Meyers, K. (1992). Pynchon's parable: the american dream in The crying of lot 49. 18(1): 3944. Literatura estadounidense, Thomas Pychon, The crying of lot 49.

Meyers, K. (1993). Chopin's choices and challenges: language and limits in "A point at issue". 19(1): 77-85. Literatura estadounidense, Kate Chopin.

Miranda, A. (1978). Para la poética. 4(2): 59-63. Poética, Henri Meeschonnic, Pour la poétique I.

Miranda, A. (1979). Reseña. 5(1-2): 73-82. Poética, Henri Meschonnic, Pour la poétique II, Epistemologie de l'éscriture poétique de la traduction.

Miranda, G. (1975). El probiema de ia enunciación del yo lírico en el "Beatus Ille" de Quinto Horacio Flaco. 1(2): 81-91. Literatura latina, Quinto Horacio Flaco.

Molina, C. (1986). Voz, fluir de la conciencia y psicoanálisis en la novela Sangre de amor correspondido de Manuel Puig. 12(2): 61-74. Literatura argentina, Manuel Puig, Sangre de amor correspondido, psicoanálisis.

Molina, M. (1986 (ANEJO)). Del color de la tierra. 12(1): 56. Literatura costarricense, creación, poesía. 
Molina, M. (1993). Rompecabezas o símbolos en el lenguaje natural. 19(1): 137-55. Ciencias cognoscitivas, lenguaje natural.

Montanaro, O. (1982). Los niveles narrativos y la persona del narrador en un corpus de Jorge Luis Borges. 8(1-2): 45-64. Literatura argentina, Jorge Luis Borges, narrador, niveles narrativos.

Montanaro, O. (1983). Análisis de la voz narrativa en "Un informe para una acandemia" de Kafka y "El infierno de Brodie" de Borges. 9(1): 57-66. Literatura comparada, Franz Kafka, Jorge Luis Borges.

Montanaro, O. (1986). Un análisis retórico de La raza cósmica de Vasconcelos. 12(1): 19-26. Literatura mexicana, José Vasconcelos, La raza cósmica.

Montanaro, O. (1987). El martirio del pastor. Auto sacramenal con sentido épico. 13(1): 47-62. Literatura costaricense, Samuel Rovinski, El martirio del pastor.

Montanaro, O. (1988). La intertextualidad y su evolución conceptual. 14(1): 11-7. Teoría literaria, intertextualidad.

Montanaro, O. (1989). "Las hojas del ciprés": clausura del proyecto literario de Jorge Luis Borges. 15(2): 7-12. Literatura argentina, Jorge Luis Borges, Los conjurados.

Montanaro, O. (1990). Historia universal de la infamia de Borges: un estudio prefacial. 16(1): 25-37. Literatura argentina, Jorge Luis Borges, Historia universal de la Infamia.

Montanaro, O. (1994). La voz narrativa de los mecanismos develadores en Historia universal de la infamia de Borges. 20(2): 87-108. Literatura argentina, Jorge Luis Borges, Historia universal de la infamia.

Mora, A. (1980). "Verte y no verte": fatalismo mahometano, revelado por la descripción semántico-estructural. 6(1-2): 47-68. Literatura española, Rafael Alberti.

Mora, A. (1981). Sobre los ángeles. 7(1-2): 49-58. Literatura española, Rafael Alberti, Sobre los ángeles.

Morales, H. (1989). Carpentier y la estructura de la historia. 15(1): 35-9. Literatura cubana, Alejo Carpentier, El reino de este mundo, Los pasos perdidos, El siglo de las luces.

Morestin, M. (1993). La lengua y los lenguajes en Cristóbal Nonato de Carlos Fuentes. 19(2): 39-55. Literatura mexicana, Carlos Fuentes, Cristóbal Nonato. 
Morestín, F. (1992). Andanzas, viandanzas, imbricaciones e hibridaciones territoriales y lingüísticas en Cristóbal Nonato de Carlos Fuentes. 18(2): 25-40. Literatura mexicana, Carlos Fuentes, Cristóbal Nonato.

Müller, M. (1985). Historia de Mayta: la novela de una novela. 11(2): 7-13. Literatura peruana, Mario Vargas Llosa, Historia de Mayta.

Murillo, J. (1992). El romance sonámbulo de Federico García Lorca: una búsqueda de la sacralidad cósmica. 18(2): 17-23. Literatura española, Federico García Lorca, El romance sonámbulo.

Murillo, J. (1994). Algunas consideraciones teóricas sobre el desarrollo del componente oral en la enseñanza de segundas lenguas. 20(2): 215-31. Lingüística aplicada, enseñanza y aprendizaje de lenguas, componente oral.

Narval, R. (1986 (ANEJO)). La muerte del boyero. 12(1): 58. Literatura costarricense, creación, poesía.

Ortiz, M. (1985). La parodia al Discurso del método de René Descartes, en El recurso del método de Alejo Carpertier. 11(2): 29-44. Literatura cubana, Alejo Carpentier, Recurso del método.

Ortiz, M. (1986). La concepción de lo real maravilloso en Alejo Carpentier: una lectura del Recurso del método. 12(2): 25-43. Literatura cubana, Alejo Carpentier, Recurso del método, real maravilloso.

Ortiz, M. (1987). La fraternidad del yo lírico en Canciones cotidianas, poemario de Jorge Debravo. 13(1): 31-45. Literatura costarricense, Jorge Debravo, Canciones cotidianas.

Ortiz, M. (1988). La parodia a la obra En busca del tiempo perdido de Proust y al "Matadero" de Esteban Echeverría en el texto de Alejo Carpentier. 14(2): 55-61. Literatura comparada, literatura cubana, literatura francesa, literatura argentina, Alejo Carpentier, Marcel Proust, Esteban Echeverría, Recurso del método, En busca del tiempo perdido, "El matadero".

Ortiz, M. (1989). El mestizaje como identidad latinoamericana en el Recurso del método de Alejo Carpentier. 15(1): 15-30. Literatura cubana, Alejo Carpentier, Recurso del método.

Ortiz, M. (1989). La cita y la reminiscencia como forma de intertextualidad en el Recurso del método de Alejo Carpentier. 15(2): 13-22. Literatura cubana, Alejo Carpentier, Recurso del método.

Ortiz, M. (1990). Octavio Jiménez en el Repertorio americano: una concepción de cultura. 16(1): 39-44. Literatura costarricense, Octavio Jiménez, Repertorio americano. 
Pacheco, G. (1986). La actitud antiguerrera en la novela Farewell to arms de Ernest Hemingway y Slaughter house-five de Kurt Vonnegut. 12(1): 65-8. Literatura estadounidense, Ernest Hemingway, Kurt Vonnegut, Farawell to arms, Slaughter house-five.

Pacheco, G. (1988). Un enfoque feminista sobre Viaje de un largo día hacia la noche. 14(1): 75-80. Literatura estadounidense, Eugene O'Neil, Viaje de un largo día hacia la noche.

Pacheco, G. (1990). The lost steps of The great Gatsby. 16(2): 27-33. Literatura comparada, literatura estadounidense, literatura cubana, F. Scott Fitzgerald, Alejo Carpentier, The great Gatsby, Los pasos perdidos.

Pacheco, G. (1994). El verdadero "Yo" en la agonía: La muerte de Artemio Cruz y El arpa y la sombra. 20(2): 109-19. Literatura comparada, literatura mexicana, literatura cubana, Carlos Fuentes, Alejo Carpentier, La muerte de Artemio Cruz, El arpa y la sombra.

Pacheco, G. (1995). The female image in Eugene O'Neill's Desire under the elms and A moon for the misbegotten. 21(1): 55-63. Literatura estadounidense, Eugene O'Neill, Desire under the elms, A moon for the misbegotten.

Pazos, E. y M. Álvarez (1977). Historia y vudú: dos perspectivas vitales en El reino de este mundo. 3(2): 1-21. Literatura cubana, Alejo Carpentier, El reino de este mundo.

Pendones, C. (1987). Análisis fonético connotativo: la / t / / en el español de Costa Rica. 13(2): 119-46. Español de Costa Rica, fonología, actitudes lingüísticas, fonema / t $/$.

Pereira, J. (1986 (ANEJO)). Esperanza; Pienso; Virginia. 12(1): 59. Literatura costarricense, creación, poesía.

Pérez, M. (1981). La semiología de la productividad y la teoría del texto de Julia Kristeva. 7(12): 59-77. Teoría literaria, semiología, Julia Kristeva.

Pérez, M. (1983). Cocorí: un narrador fuertemente representado y una comunidad de narratorios infantiles. 9(2): 3-14. Literatura costarricense, Joaquín Gutiérrez, Cocorí.

Pérez, M. (1983). Ironía, dependencia y humor en la producción significante latinoamericana. 9(1): 155-66. Ironía.

Pérez, M. (1984). Entre la tradición y la ruptura: Manuel Argüello Mora, un humanista del siglo XIX. 10(2): 63-87. Literatura costarricense, Manuel Argüello Mora.

Pérez, M. (1995). Cuentos del Tárcoles: la huella del tiempo, realidades y realismos. 21(2): 5981. Literatura costarricense, Carlos Luis Altamirano, Cuentos del Tárcoles. 
Pérez, R. (1988). Sintagmas y paradigmas en La consagración de la primavera de Alejo Carpentier. 14(2): 25-53. Literatura cubana, Alejo Carpentier, La consagración de la primavera.

Picado, M. (1975). El estudio de la literatura a través de la historia. 1(2): 93-6. Teoría literaria.

Picado, M. (1975). La estilística de Amado Alonso. 1(2): 97-102. Estilística, poética.

Picado, M. (1975). Trayectoria poética de Jorge Debravo. 1(1): 7-14. Literatura costarricense, Jorge Debravo.

Picado, M. (1978). Pedro Arnáez: relato tradicional. 4(1): 17-39. Literatura costrricense, Pedro Arnáez.

Portilla, M. (1987) Tipología de los sistemas vocálicos románicos. 13(2): 109-18. Tipología, fonología, lenguas romances.

Portilla, M. (1989). Bibliografía sobre fonética y fonología hispanoamericanas. 15(1): 79-97. Fonética, fonología, dialectología, historia de la lingüística.

Portilla, M. (1993). Fonemas segmentales en el criollo inglés de Limón. 19(2): 89-97. Fonología, criollo inglés de Limón.

Portilla, M. (1995). Tono en el criollo inglés de Costa Rica. 21(1): 135-9. Criollo inglés de Limón, fonología, tono.

Pütz, M. (1990). Henry David Thoreau's critique of expansionist ideology. 16(1): 151-60. Literatura estadounidense, Henry David Throreau.

Quesada, A. (1983a). Actitud crítica en el costumbrismo costarricense. 9(1): 67-74. Literatura costarricense, costumbrismo.

Quesada, A. (1983b). Dos cuentos de Fernández Guardia: "El estreno" y "La política". 9(1): 135-44. Literatura costarricense, Ricardo Fernández Guardia.

Quesada, A. (1984). Reflexiones acerca de la polémica sobre nacionalismo literario. 10(1): 313. Literatura costarricense, historia de la literatura.

Quesada, A. (1986). Los jóvenes ácratas, los viejos liberales y el movimiento obrero en Costa Rica (1900-1914). 12(1): 191-200. Literatura costarricense, historia de la literatura.

Quesada, A. (1988). La muerte de Tolstoi en la prensa costarricense. 14(2): 172-82. León Tolstoi.

Quesada, A. (1988). Lectura histórica de El árbol enfermo. 14(1): 51-9. Literatura costarricense, Carlos Gagini, El árbol enfermo. 
Quesada, A. (1995). Nación y enajenación: modelos de identidad en la literatura costarricense. 21(2): 41-57. Literatura costarricense.

Quesada, J. (1988). Análisis sociolingüístico de la /s/ en el área metropolitana de San José. 14(2): 167-72. Sociolingüística, fonema /s/, español de Costa Rica.

Quesada, J. (1989). Aportes de la lingüística al estudio del discurso persuasivo. 15(1): 145-7. Análisis del discurso, discurso persuasivo.

Quesada, J. (1992). Functions of repetition in two western languages: English and spanish. 18(1): 163-76. Comparación del español y del inglés.

Quesada, M. (1987). El español de Juan Vásquez de Coronado: Análisis descriptivo. 13(1): 167-82. Español colonial, Juan Vásquez de Coronado.

Quesada, M. (1987). Léxico ganadero de la Costa Rica colonial. 13(2): 147-56. Español colonial, lexicografía, español ganadero.

Quesada, M. (1988). Uso de las formas de tratamiento en cartas privadas escritas en América en el siglo XVI. 14(2): 123-8. Español de Costa Rica, español colonial, formas de tratamiento.

Quesada, M. (1989). La rayectoria lingüística de Carlos Gagini. 15(1): 127-44. Carlos Gagini, historia de la lingüística.

Quesada, M. (1992). Pequeño Atlas lingüístico de Costa Rica. 18(2): 85-189. Español de Costa Rica, atlas lingüístico de Costa Rica.

Quesada, S. (1995). Intertextualidad y producción de sentido en Viaje al reino de los deseos. 21(1): 65-76. Literatura costarricense, Rafael Ángel Herra, Viaje al reino de los deseos.

Quesada, U. (1986 (ANEJO)). Soñar lo soñado. 12(1): 13-4. Literatura costarricense, creación, cuento.

Quirós, J. (1985). Observaciones sobre la tipología de la lengua chorotega o mangue. 11(2): 937. Lenguas indígenas de Costa Rica y Nicaragua, chorotega, mangue, tipología.

Quirós, J. (1986). Cinco variantes guanacastecas del tipo 510 de Aarne y Thompson (“La cenicienta" y "Piel de asno"). 12(2): 155-71. Narración folclórica.

Quirós, J. (1986). Etimología de los nombres "chorotega", "mangue” y "diriá". 12(1): 151-2. Lengua índigena de Costa Rica y Nicaragua, chorotega, etimología. 
Quirós, J. (1988). El sistema vocálico de la lengua chorotega o mangue. 14(2): 129-32. Lenguas indígenas de Costa Rica y Nicaragua, chorotega, fonología.

Quirós, J. (1993). La danza de las trece princesas: versión guanacasteca de un viejo cuento europeo. 19(1): 129-33. Narración folclórica.

Quirós, M. (1975). Algunos elementos lexicales no latinos en el idioma español. 1(2): 103-18. Español, préstamos léxicos.

Quirós, M. (1975). Vida de las palabras. 1(1): 15-20. Español, etimología.

Quirós, M. (1980). Castilla y el castellano, origen de un lugar, un idioma y un nombre. 6(1-2): 81-97. Español, historia de la lengua.

Quirós, M. (1982). Poesía y música en Bernardo de Ventadorn, poeta trovadoresco. 8(1-2): 915. Literatura provenzal, poesía trovadoresca, Bernardo de Ventadorn.

Quirós, M. (1984). Origen y formación de la lengua catalana. 10(1): 57-74. Catalán, historia de la lengua.

Quirós, M. (1985). Alfonso X el sabio y el romance castellano. 11(1): 15-28. Español, historia de la lengua, Alfonso X el sabio.

Quirós, M. (1986). Las glosas de Reichenau. 12(1): 43-50. Latín, glosario, Glosas de Reichenau.

Quirós, M. (1988). La elaboración de etimologías romances a partir del latín. 14(2): 77-85. Latín, etimología.

Quirós, M. (1989). El paso del latín al romance y fijación escrita de este. 15(1): 67-76. Latín.

Quirós, M. (1995). El latín en la música. 21(2): 131-57. Latín.

Quirós, S. (1987). Carlos Gagini y su ideología antiimperialista en La caída del águila. 13(2): 51-60. Literatura costarricense, Carlos Gagini, La caída del águila.

Quirós, S. (1990). Carlos Gagini: La caída del águila y su concepto de la paz mundial. 16(1): 12-24. Literatura costarricense, Carlos Gagini, La caída del águila.

Quirós, S. (1993). La danza de las trece princesas: versión guanacasteca de un viejo cuento europeo. 19(1): 129-33. Narrativa oral.

Quirós, X. (1985). Algunas consideraciones sobre el discurso indirecto en el Bellum Gallicum de C. Julius Caesar. 11(2): 71-3. Literatura latina, Cayo Julio César, Bellum Gallicum. 
Robles, I. (1984). El estatuto isotópico y el universo homogéneo de El llano en llamas. 10(1): 31-55. Literatura mexicana, Juan Rulfo, El llano en llamas.

Robles, I. (1994). Adán, el Edén y Abel o la estructura narrativa simbólica de las Cartas de Relación de Hernán Cortés. 20(2): 31-45. Hernán Cortés, Cartas de Relación.

Robles, I. (1994). Las Cartas de Relación de Hernán Cortés: el entorno de producción, la intitulación y la circulación (Diagnosis). 20(1): 7-23. Hernán Cortés, Cartas de Relación.

Rodríguez, E. y E. Margery (1985). Indíce de volúmenes I a X. 11(1): 149-61. Bibliografía.

Rodríguez, F. (1993). La poesía posvanguardista latinoamericana: notas para un acercamiento a la lírica conversacional. 19(1): 35-47. Literatura latinoamericana, literatura nicaragüense, José Coronel Urtecho, posvanguardismo.

Rodríguez, F. (1994). El código del exilio en Los ojos del pájaro quemado de Jorge Boccarena. 20(2): 73-85. Literatura argentina, Jorge Boccarena, Los ojos del pájaro quemado.

Rodríguez, F. y. C. Villalobos. (1991). Evocación e intertextualidad en La guerra prodigiosa. 17(1-2): 55-61. Literatura costarricense, Rafael Angel Herra, La guerra prodigiosa, sociocrítica.

Rodríguez, M. (1981). Perspectivas narrativas y disposición temporal en "El hombre" de Juan Rulfo. 7(1-2): 3-12. Literatura mexicana, Juan Rulfo, El llano en llamas.

Rodríguez, M. (1983). Análisis del poema "Unidad en ella" de Vivente Aleixandre. 9(1): 10322. Literatura española, Vicente Aleixandre.

Rodríguez, M. (1985). Una aproximación crítica a Los funerales de la mamá grande de Gabriel García Márquez. 11(2): 15-28. Literatura colombiana, Gabriel García Márquez, Los funerales de la mamá grande.

Rodríguez, M. (1986). Eficaz plan para resolver la desnutrición infantil y de paso los problemas fiscales: una sátira a la alienación colectiva. 12(1): 27-39. Literatura costarricense, Alberto Cañas, Eficaz plan para resolver la desnutrición infantil y de paso los problemas fiscales.

Rodríguez, M. (1988). América latina, crítica literaria e identidad. 14(2): 19-23. Literatura latinoamericana, teoría literaria.

Rodríguez, M. (1988). El Periquillo Sarniento: la novela latinoamericana en busca de su identidad. 14(1): 45-9. Literatura mexicana, José Joaquín Fernández de Lizardi, El Periquillo Sarniento. 
Rodríguez, M. y C. Valverde. (1981). Los estilos indirecto y directo libres: un aporte a su definición. 7(1-2): 43-8. Estilo directo, estilo indirecto.

Ross, R. (1977). La simplificación de reglas como mecanismo del cambio lingüístico: un ejemplo del español de Costa Rica. 3(2): 93-5. Español de Costa Rica, cambio lingüístico.

Ross, R. (1987). El caso de "Haber". 13(2): 105-8. Español, morfosintaxis.

Ross, R. y J. Umaña (1991). La desaparición del subjuntivo español y sus implicaciones para el cambio linguiístico. 17(1-2): 193-202. Español de Costa Rica, subjuntivo, cambio lingüístico.

Rubio, C. (1986 (ANEJO)). A tu soledad me entrego. 12(1): 60. Literatura costarricense, creación, poesía.

Sagot, J. (1986 (ANEJO)). La inopinada decisión del estudiante de piano. 12(1): 21-5. Literatura costarricense, creación, cuento.

Salas, A. (1990). La traducción de Shakespeare en Costa Rica: estudio comparativo de dos traducciones de El rey Lear. 16(2): 41-8. Literatura inglesa, Shakespeare.

Salas, A. (1992). Estado actual y perspectivas de los estudios de análisis del discurso en Costa Rica. 18(1): 133-8. Análisis del discurso, historia de la lingüística.

Salas, A. y. A. Valencia (1988). Fonología del aymará antiplánico chileno. 14(2): 119-22. Lenguas indígenas de Chile, aymará, fonología.

Sánchez, A. (1994). Lo real maravilloso americano y la estética de la recepción. 20(2): 59-72. Literatura cubana, Alejo Carpentier, real maravilloso.

Sánchez, M. (1989). Desire under the elms as a celebration of life: a view in the light of Nietzsche's The birth of tragedy. 15(2): 31-5. Literatura estadounidense, Eugene O'Neill, Desire under the elms.

Sánchez, M. (1993). Reading literary works in a second language: transaction and interaction. 19(2): 63-8. Teoría literaria, teoría del esquema, teoría transaccional.

Sánchez, V. (1977). La partícula an y el período hipotético irreal en el griego clásico. 3(2): 636. Griego, morfosintaxis.

Sánchez, V. (1979). El maleku: lengua ergativa. 5(1-2): 67-71. Lenguas indígenas de Costa Rica, guatuso, morfosintaxis, ergatividad.

Sánchez, V. (1981). Un problema de semántica: la neutralización presente / pasado en castellano. 7(1-2): 93-9. Español, tiempo, aspecto. 
Sánchez, V. (1983a). El optativo en griego clásico. 9(2): 73-81. Griego, modo.

Sánchez, V. (1983b). Herencia común y diferenciación léxicas latinas en la Romania lateral. 9(2): 35-62. Léxico, español, rumano.

Sánchez, V. (1983c). Lexicología latina en rumano y español: un capítulo de historia de lingüística románica. 9(2): 63-72. Léxicología, español, rumano.

Sánchez, V. (1985). Fricación de erre en el español de Costa Rica: un caso de escisión fonológica. 11(1): 63-6. Español de Costa Rica, fonema / r /, fonología.

Sánchez, V. (1985). Teoría lingüística y enseñanza de lenguas clásicas en la Universidad de Costa Rica. 11(2): 75-7. Lenguas clásicas, historia de la lingüística.

Sánchez, V. (1986). Escisión fonológica de / r / en el español de Costa Rica. 12(2): 129-37. Español de Costa Rica, fonema / r/, fonología.

Sánchez, V. (1986). Estudios en Costa Rica sobre lengua castellana: de Gagini a Agüero. 12(1): 125-32. Historia de la lingüística.

Sánchez, V. (1987). La ambigüedad como mecanismo del cambio lingüístico. 13(1): 163-6. Ambigüedad lingüística, cambio lingüístico, español de Costa Rica.

Sánchez, V. (1988). Lexicografía del español en Costa Rica, visión crítica. 14(2): 147-56. Lexicografía, historia de la lingüística.

Sánchez, V. (1989). La lengua española en la educación costarricense, redefinición. 15(2): 155 61. Español, políticas lingüísticas.

Sánchez, V. (1994). La categoría morfosintáctica número en el sustantivo español. 20(1): 155 68. Español, sustantivo, número.

Sancho, L. (1992). Don Quijote: ejecutar un acto o la escritura de una interpretación. 18(1): 19-29. Literatura española, Miguel de Cervantes, El Quijote.

Sandoval, V. (1975). Hombres de maíz, trascedentalización de la existencia. 1(1): 3-6. Literatura guatemalteca, Miguel Angel Asturias, Hombres de maiz.

Sandoval, V. (1976). "El Jesús malo" no era tan malo (sobre un cuento de Ricardo Miró). 2(1): 10-5. Literatura panameña, Ricardo Miró.

Sandoval, V. (1983). En el séptimo círculo o el drama interminable de la violencia (Drama social de Daniel Gallegos). 9(1): 21-56. Literatura costarricense, Daniel Gallegos, En el séptimo círculo. 
Sandoval, V. (1987). Discurso de incorporación a la Academia Costarricense de la Lengua. 13(1): 185-94. Academia costarricense de la Lengua, Carlos Gagini, Don Concepción.

Sandoval, V. (1990). Respuesta de la secretaría de la Academia Costarricense de la Lengua al discurso de don Jézer González Picado. 16(2): 135-6.

Santander, C. (1985). El arpa y la sombra en la poética de Carpentier. 11(2): 45-51. Literatura cubana, Alejo Carpentier, El arpa y la sombra.

Segura, E. (1978). La cuestión de la incorporeidad del noûs en el pensamiento de Anaxágoras. 4(1): 75-86. Anaxágoras.

Segura, E. (1986). Unidad y ser en Platón (notas al Parménides ). 12(2): 81-4. Platón, Parménides.

Senior, A. (1994) La mujer-madre de Leopold Sédar Senghor y el matriarcado en la literatura francófona. 20(1): 51-65. Literatura senegalesa, Leopold Sédar Senghor, Poèmes.

Senior, A. (1995). La mujer-texto en Como agua para chocolate. 21(1): 47-54. Literatura mexicana, Laura Esquivel, Como agua para chocolate.

Smith, H. (1979). Un análisis fonológico del maleku. 5(1-2): 31-54. Lenguas indígenas de Costa Rica, maleku, fonología

Smith, H. y. T. Zamora. (1979). Un análisis tagmemático del dialecto nobere del guaymí. 5(12): 125-37. Lenguas indígenas de Costa Rica, guaymí, morfosintaxis.

Sojo, C. (1986 (ANEJO)). Poesías para niños. 12(1): 61. Literatura costarricense, creación, poesía.

Solano, Y. (1982). Literatura e historia en Facundo. 8(1-2): 65-73. Literatura argentina, Domingo Faustino Sarmiento, Facundo.

Solano, Y. (1986). Una variación lingüística en el habla costarricense. 12(1): 133-43. Español de Costa Rica, fonología, vocales finales átonas [o-u] y [e-i].

Solano, Y. (1988). Acercamiento a un discurso pedagógico-religioso del siglo XVI: La cartilla para enseñar a leer, de Fray Pedro de Gante. 14(2): 157-66. Historia de la lingüística, Fray Pedro de Gante, La cartilla para enseñar a leer.

Solano, Y. (1989). Los conectores pragmáticos en el habla culta costarricense. 15(2): 143-54. Español de Costa Rica, habla culta, pragmática, morfosintaxis.

Solano, Y. (1990). El orden de las palabras en español. 16(1): 113-26. Español, morfosintaxis. 
Solano, Y. (1991). Las formas nexuales adversativas en el habla culta costarricense. 17(1-2): 219-34. Español de Costa Rica, habla culta, morfosintaxis.

Solano, Y. y J. Umaña (1994). Inseguridad lingüística del universitario costarricense. 20(1): 169-78. Español de Costa Rica, actitudes lingüísticas.

Solís, J. (1986 (ANEJO)). Noche de carne; Piel sobre piel; Pirámide azul. 12(1): 63-4. Literatura costarricense, creación, poesía.

Solís, M. (1986 (ANEJO)). Poesía. 12(1): 65. Literatura costarricense, creación, poesía.

Soto, R. (1986 (ANEJO)). Imaginación y creación. 12(1): 31-3. Literatura costarricense, creación, ensayo.

Sparisci, L. (1986). "Excerpta" de oratoria romana. 12(2): 85-90. Literatura latina, período preciceroneano, oratoria.

Sparisci, L. (1989). Escuelas y representantes de la filología. 15(1): 151-4. Historia de la filología.

Stark, D. (1977). El individuo y los sistemas políticos a través de tres novelas de Joseph Conrad. 3(2): 51-61. Literatura inglesa, novela política, Joseph Conrad.

Trejos, E. (1987). El barroco en Los pasos Perdidos. 13(1): 97-111. Literatura cubana, Alejo Carpentier, Los pasos Perdidos.

Trejos, E. (1987). Semejante a la noche -Historia y temporalidad. 13(2): 25-33. Literatura cubana, Alejo Carpentier, Semejante a la noche.

Umaña, J. (1988). En torno a los métodos de la sociolingüística. 14(1): 83-94. Teoría lingüística, sociolingüística.

Umaña, J. (1989). La relación entre actitudes lingüísticas, conducta e identidad. 15(2): 121-9. Sociolingüística, psicología social, actidudes lingüísticas.

Umaña, J. (1990). Grupos portadores de actitudes linguísticas. 16(2): 103-9. Sociolingüística, psicología social, actitudes lingüísticas.

Umaña, J. (1990). Variación de vibrantes en una muestra del habla de clase media costarricense. 16(1): 139-48. Español de Costa Rica, fonema / r /, sociolingüística.

Umaña, J. (1991). La historia de vida como unidad de análisis lingüístico. 17(1-2): 125-36. Narrativa oral, análisis del discurso. 
Umaña, J. (1994). "La aventura en la finca": aproximación múltiple a una narración oral infantil. 20(1): 143-53. Narrativa oral, análisis del discurso.

Ureña, C. (1977). Carlos Gagini Chavarría (1865-1925). 3(1): 3-4. Biografía.

Valembois, V. (1979). Ideas exóticas y teatro exótico: el caso de centroamérica. 5(1-2): 60-6. Literatura centroamericana.

Valembois, V. (1981). La crítica teatral: su espacio sígnico (el caso de Costa Rica). 7(1-2): 8792. Teatro, crítica teatral.

Vargas, A. (1981). Luces de bohemia. 7(1-2): 83-5. Literatura española, Ramón del Valle-Inclán, Luces de bohemia.

Vargas, C. (1988). Aspectos del programa lingüístico general de Montague. 14(2): 133-46. Teoría lingüística, Montague.

Vargas, C. (1988). Gramática de estructura sintagmática generalizada (GESG). 14(1): 95-108. Gramática generativa transformacional, Gerard Gazdar, Jeffrey Pullum.

Vargas, C. (1989). Gramáticas indizadas y lenguas naturales. 15(1): 99-105. Teoría lingüística.

Vargas, C. (1992). La utilización de formalismos basados en unificación para el análisis de las lenguas naturales. 18(2): 71-83. Gramáticas categoriales.

Vargas, J. (1993). El general en su laberinto: un acercamiento a la realidad latinoamericana. 19(2): 31-8. Literatura colombiana, Gabriel García Márquez, El general en su laberinto.

Vargas, J. (1993). La verosimilitud. 19(1): 7-16. Teoría literaria.

Vargas, J. (1994). España: en tu temblor de la tragedia yo miro sangre de gloria. 20(2): 47-57. Literatura costarricense, Guerra Civil Española.

Vargas, M. (1982). Apuntes acerca de "La propia" de Magón. 8(1-2): 27-30. Literatura costarricense, Manuel González Zeledón.

Vargas, X. (1986 (ANEJO)). Día 24. 12(1): 66. Literatura costarricense, creación, poesía.

Vásquez, M. (1993). Construyendo un mundo a través de la literatura para niños. 19(2): 17-29. Literatura infantil, literatura costarricense, Adela Ferreto.

Vega, V. (1984). Laboratorio de lenguas: nuevas perspectivas de utilización. 10(1): 75-81. Lingüística aplicada. 
Vega, V. (1990). Factores psicológicos que intervienen en el aprendizaje de lenguas extranjeras. 16(1): 139-48. Psicología social, enseñanza y aprendizaje de lenguas.

Villalobos, C. (1994). Utopía y crítica en los textos de Sábato. 20(1): 35-48. Literatura argentina, Ernesto Sábato, Abaddón el exterminador.

Vindas, F. (1977). La libertad en el mundo antiguo . 3(1): 54-68. Historia del pensamiento.

Vindas, F. (1978). Marcia y Cornelia en el poema de Lucano. 4(2): 25-30. Literatura latina, Marco Anneo Lucano, La Farsalia.

Vindas, F. (1978). Sempronia en la conjuración de Catilina. 4(1): 13-6. Literatura latina.

Víquez, A. (1986 (ANEJO)). Las actitudes de los cuerdos. 12(1): 17-9. Literatura costarricense, creación, cuento.

Víquez, A. (1993). El libro de buen amor: más allá del tratado didáctico-moralizante o su parodia. 19(1): 17-24. Literatura española, Arcipreste de Hita, El libro de buen amor.

Víquez, A. (1994). La lectura borgesiana del Quijote. 20(2): 19-30. Don Quijote de la Mancha, literatura argentina, Jorge Luis Borges.

Wedel, A. (1992). El prejuicio y la tradición literaria: el autor alemán Moscherosch y los "Wälsche" del siglo XVII. 18(1): 33-7. Literatura alemana, Hans Michael Moscherosch, Philander von Sittenwald.

Wedel, A. (1993). La germanofobia de Vicente Blasco en Los cuatro jinetes del Apocalipsis. 19(2): 57-62. Literatura española, Vicente Blasco, Los cuatro jinetes del Apocalipsis.

Wilson, J. (1975a). Gramática generativa del frisón. 1(2): 119-34. Frisón, morfosintaxis.

Wilson, J. (1975b). Nueva formulación de la Ley de Grimm. 1(2): 143-8. Ley de Grimm, cambio lingüístico.

Wilson, J. (1975c). Sobre la naturaleza del lenguaje. 1(2): 135-42. Teoría lingüística.

Wilson, J. (1980). El español de Costa Rica: estudio fonológico generativo. 6(1-2): 3-46. Español de Costa Rica, fonología.

Wilson, J. (1985). La gramática de los casos del español. 11(1): 67-89. Morfosintaxis, gramática de casos, español.

Wilson, J. (1989). Sobre el dequeísmo. 15(1): 107-13. Morfosintaxis, español, dequeísmo. 
Wilson, J. (1990). Aspect and the english modal system. 16(2): 93-102. Inglés, tiempo, modo, aspecto.

Woodward, J. (1992). Historical bases of new Costa Rican sign language. 18(1): 127-32. Lenguaje de señas en Costa Rica, historia.

Wright, F. (1975). Un análisis sintáctico del habla criolla de Limón. 1(2): 149-68. Criollo inglés de Limón, morfosintaxis.

Wright, F. (1982). Problemas y métodos para la enseñanza del inglés como segunda lengua a los hablantes de mek-a-tel-yu en la provincia de Limón. 8(1-2): 129-35. Criollo inglés de Limón, inglés, planificación lingüística.

Zemskov, V. (1989). Introducción a la Historia de las literaturas de America Latina. 15(1): 7 14. Literatura Latinoamericana, historia. 